\title{
Demonstration and the Indemonstrability of the Stoic Indemonstrables
}

\author{
Susanne Bobzien \\ All Souls College, Oxford University \\ susanne.bobzien@philosophy.ox.ac.uk
}

\begin{abstract}
Since Mates' seminal Stoic Logic there has been uncertainty and debate about how to treat the term anapodeiktos when used of Stoic syllogisms. This paper argues that the customary translation of anapodeiktos by 'indemonstrable' is accurate, and it explains why this is so. At the heart of the explanation is an argument that, contrary to what is commonly assumed, indemonstrability is rooted in the generic account of the Stoic epistemic notion of demonstration (apodeixis). Some minor insights into Stoic logic ensue.
\end{abstract}

Keywords: Stoic logic, demonstration, indemonstrables, Stoic syllogistic, Stoic epistemology

Chrysippus' five kinds of basic syllogisms. Arguably the most well-known elements of Stoic logic are Chrysippus' five kinds of anapodeiktoi, or indemonstrables, as the Greek expression is commonly rendered. ${ }^{1}$ Stoic standard examples, one of each kind, are

1. If it is day, it is light. But it is day. Hence it is light.

2. If it is day, it is light. But it is not light. Hence it is not day.

3. Not: both it is day and it is night. But it is day. Hence not: it is night.

4. Either it is day or it is night. But it is day. Hence it is not night.

5. Either it is day or it is night. But it is not night. Hence it is day.

\footnotetext{
${ }^{1}$ Some alternative translations are: 'non-demonstrables' (Bury 1933, 1935), 'undemonstrated' (Mates 1961, p.63 'unproveds' (Barnes 1980, 1985 p.431 in the 2012 reprint ('indemonstrables' in the original, 1985, p.576), 2003, p.14; 2007, e.g. p.371, p.507), 'unprovables' (Annas \& Barnes 2000), 'undemonstrateds' (Hitchcock 2006).
} 
These indemonstrables are Stoic syllogisms; that is, arguments valid due to their form. ${ }^{2}$

The incongruence problem and a solution. As has been repeatedly remarked, the Greek verbal adjective anapodeiktos, as is the case in general with adjectives formed with an alpha privative and ending in '-tos', has two possible main translations: one factive, e.g. 'undemonstrated' or 'unproved' and one expressing (absence of) potentiality or possibility: e.g. 'indemonstrable' or 'unprovable' (cf. e.g. Frede 1974, 127-9, Barnes 2007, 369). Philosophically, the difference between those two options is significant. Something that has not been proved may be provable. For example, if an axiom in a system has not been proved but is provable, it is redundant. If it is unprovable, it is not. It is reasonable to assume that the Stoics had at least unreflective knowledge of this systematic lexical ambiguity in anapodeiktos, and that they intended the word to be taken in one of these two core meanings (so also Barnes 2007, 369). Consistent with this assumption, some ancient works on logic distinguish more than one usage of anapodeiktos (SE M 8.223, Apul. Int. 205.21-206.5, both quoted below). One may think that the main question is which of the two meanings the Stoics intended; and derivatively and accordingly, what the right translation of anapodeiktos is in the context of Stoic logic. Things are more complicated, however.

Jonathan Barnes, in his 2007 tour de force through ancient logic, Truth, etc., notes that several ancient texts distinguish two meanings of anapodeiktos, but that surprisingly, the one attributed to the Stoics appears not to be a meaning anapodeiktos actually has (Barnes 2007, 370). Rather, the texts suggest that the Stoics used anapodeiktos for arguments that need no proof; a meaning the word does not carry (Barnes 2007, 370-71). So we have an expression with two grammatically attested meanings neither of which seems to be the Stoic one; and we have an attribution to the Stoics of a meaning that is not grammatically attested. How can we make sense of this incongruence?

We can assume that the Stoics themselves believed and stated that their anapodeiktoi were not in need of proof. This is well-documented in ancient texts and is not in doubt (SE $M$ 8.223, SE PH 2.156, DL 7.79). ${ }^{3}$

\footnotetext{
${ }^{2}$ For details see DL 7.80-81, SE PH 2.157-9, SE $M$ 8.224-7, Gal. Inst.Log.VI.6, [Galen] Hist.Phil.15 and Frede 1974, 137-52; Bobzien 1996, 134-41; 2019, 243-46.
} 
(A) And there are some [arguments] that are indemonstrable(s) (anapodeiktoi) since they do not need a demonstration (apodeixeōs). ${ }^{4}$ (DL 7.79)

(B) For they say [the anapodeiktoi] are the arguments which are not in need of demonstration (apodeixeōs) for the establishment of their own conclusiveness. ${ }^{5}$ (SE PH 2.156)

It is also plausible that, when calling the anapodeiktoi anapodeiktoi, the Stoics did not intend the term to mean that they need no proof. Accepting these assumptions, Barnes tentatively offers the following suggestion. With the choice of meanings of anapodeiktos for the Stoics being between 'unproved' or 'indemonstrable/unprovable', it has to be 'unproved': with this intended meaning, the Stoic claim that the anapodeiktoi are not in need of proof provides a reason for their so naming them (Barnes 2007, 370-371). ${ }^{6}$

Hitchcock 2006, p.239, fn.29, echoes Barnes' argument. Additionally, he spells out explicitly the common assumption that the Stoic terms apodeixis (proof, demonstration) and anapodeiktos signify a Stoic deduction, or result of a Stoic analysis, and its absence, respectively, and thus (it is implied) differ in meaning from the Stoic epistemic notion of apodeixis for which we find definitions elsewhere in our sources. Call this the Two-senses Assumption. The first proponent both of a translation 'undemonstrated/unproved' and of the Two-senses Assumption appears to be Benson Mates (Mates 1961, 63, see below). I have reservations both about the 'undemonstrated/unproved' translation and about the Two-senses Assumption. In what follows I offer an alternative resolution of the above-stated incongruence. It is grounded in a rejection of the Two-senses Assumption.

My starting point is textual. Barnes' and Hitchcock's explanations face a difficulty in connection with the evidence for the Stoic use reported by Sextus, who writes

\footnotetext{
${ }^{3}$ Besides these two texts, also SE $M$ 8.223, quoted below as (C); all in Barnes 2007. There seems to be indirect support in Gal. Int.Log. 8.1 and Apul. Int.205.21-206.5, quoted below as (G).

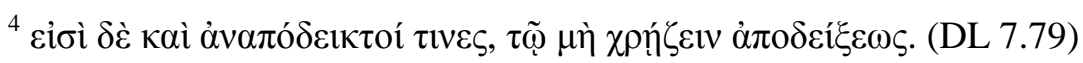

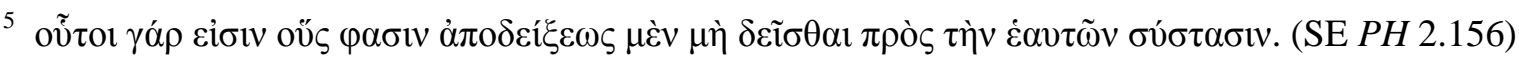

${ }^{6}$ Barnes concludes that 'the standard translation' (of anapodeiktos by 'indemonstrable') 'is demonstrably inaccurate' (Barnes 2007, 371).
} 
(C) 'Anapodeiktoi' is used of syllogisms ${ }^{7}$ in two senses, as arguments that have not been demonstrated and as arguments that have no need of demonstration because for them it is immediately evident that they conclude (i.e. are syntactically valid). ${ }^{8}$ And we have frequently indicated that [Chrysippus' anapodeiktoi] as they are set out at the beginning of the first book of his Introduction to Syllogisms are so called by the second sense. ${ }^{9}$ (SE $M$ 8.223)

Sextus does not just state generically that anapodeiktos has two senses. He is more specific: It is arguments or syllogisms of which anapodeiktos 'is used ... in two senses', as is implied by the nominative masculine plural. This suggests that we get a historically based report on an element of ancient logic. It is likely that the report is of two philosophical uses, each calling some valid arguments anapodeiktoi but in a different sense, where the second includes the Stoic position held by Chrysippus. In the first use, anapodeiktoi are so named, since the arguments have not been demonstrated. This is straightforward ancient Greek. I am not concerned here with whose view this may have been. ${ }^{10}$ Sextus' description of the second view is more complex in that it includes a reason why anapodeiktoi are said not to need demonstration ('because ...').

Barnes' suggested rendering 'unproved' makes this part of (C) more perplexing than a translation as 'indemonstrable' or 'unprovable' would. Sextus' distinction appears to be

\footnotetext{
${ }^{7}$ The nominative plural masculine requires some masculine noun. The context provides logos ('argument') in SE M 8.224-5. Alternatively, the book title by Chrysippus mentioned at the end of SE M 8.223, Introduction to Syllogisms, makes sullogismos ('syllogism') another option, which is preferred by Barnes 2007, 372. Either way the arguments at issue are valid arguments, and we know that the Stoic anapodeiktoi were syllogisms.

${ }^{8}$ Conclude the conclusion from the premises, that is. Cf. SE $M$ 8.228.

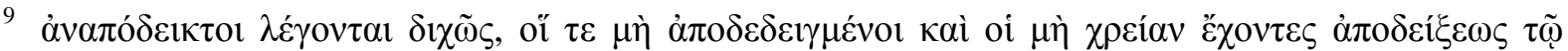

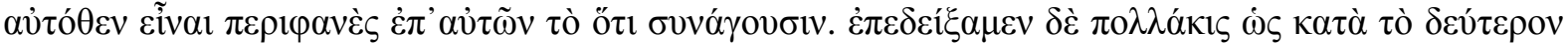

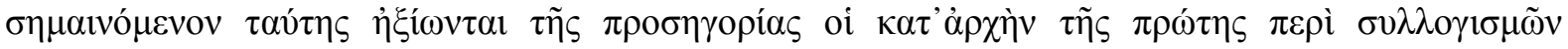

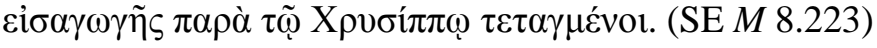

${ }^{10}$ Aristotle uses anapodeiktos in his syllogistic at An.Pr. $53^{\mathrm{a}} 32$ and ${ }^{\mathrm{b}} 2$, where it appears to have the sense 'undemonstrated' (so also Barnes 1994, 95). Elsewhere Aristotle uses it with the sense 'indemonstrable'. In the Eudemian Ethics, he takes explicit note of the two senses of expressions with an alpha privative ending in '-tos' (Arist. EE III 1, 1230 ${ }^{\mathrm{b}} 1-3$ ). Later Peripatetics and Peripateticinspired authors link the perfection of a syllogism with its indemonstrability (cf. Barnes et al 1991, 48 fn.45) and with no need for a demonstration (so Galen and Alexander of Aphrodisias, see Barnes 2007, 371-2).
} 
between two different intended meanings for valid arguments or syllogisms. Barnes' reading makes both uses of anapodeiktos have the same intended meaning, namely 'unproved' or 'undemonstrated'. They are distinct insofar as in the second use, but not the first, the arguments are said to be unproved for the reason that they are not in need of proof. This sits uncomfortably with Sextus' 'legontai dichōs', which is commonly found for expressions that are employed with two different meanings - not for expressions used with the same intended meaning but used in that meaning for different reasons. (The point applies mutatis mutandis to Hitchcock 2006.)

So this textual point suggests that it may be worth looking for an alternative explanation of the apparent incongruence of the Stoic use or understanding of anapodeiktos with which I started the paper. My aim is to show that there are philosophical reasons that endow the rendering 'indemonstrable' of the Stoic anapodeiktos with perfect sense. Here it helps to recall that the Greek anapodeiktos is cognate with apodeixis. In Stoic logic, apodeixis ('demonstration') is an epistemic term, i.e. a term that concerns cognition, and not a purely logical term. The generally very reliable summary of Stoic logic in Diogenes has

(D) A demonstration is an argument (logos) that [validly] concludes (perainonta) from what is more easily grasped (katalambanomenonn) that which is less easily grasped. ${ }^{11}$ (DL 7.45)

The verb 'to grasp' (katalambanein) is the Stoic term for factive cognition that falls short of knowledge, the latter being reserved for the sages. Sextus reports an almost certainly Stoic definition of apodeixis (this is supported by terminology and context) that is both less generic and adds more detail: ${ }^{12}$

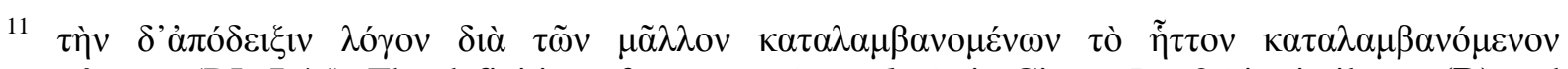

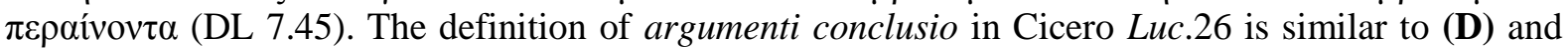
likely to be Stoic.

${ }^{12}$ Cf. Barnes 1980, Allen 2008, part III.5, and Hankinson 2009, 209, 212, for discussion of apodeixis in Hellenistic philosophy. 
(E) A demonstration is, they say, an argument $(\log o s)$ which reveals by concluding (kata sunagōgēn) a non-evident (adèlon) conclusion on the basis of agreed premises. ${ }^{13}$ (SE $P H 2.135$, cf. SE $P H 2.143$ )

Definition (E) is a variant of (D). It is less generic, since the definition in (D) allows for degrees of ease of grasping, whereas in (E) the underlying distinction is simply between what is evident and what is non-evident and can be revealed. Both definitions agree that demonstrations (apodeixeis) are valid arguments: they conclude (perainein) or afford a concluding (sunagōge $).{ }^{14}$ Text (E) is followed by a step-by-step explanation of the definition that culminates in the semi-schematically presented example of a demonstration, or demonstrative argument (apodeiktikos logos).

(F) If sweat flows through the surface, there are imperceptible pores. But the first. Therefore the second. ${ }^{15}$ (SE PH 2.142, tr. Annas \& Barnes)

Both definitions characterize demonstration (apodeixis) in epistemic terms: ease of grasping and the non-evidence or unclarity of the conclusion together with its being revealed (ekkaluptomenon, SE PH 2.143, cf. 142); this is contrasted with the conclusion being evident or clear (prodēlon, ibid. 140). Now, Stoic terminology is rarely random, and uses of groups of cognates for the explanation or reference to the same philosophical notion abound. It is most plausible then that the Stoic term anapodeiktos was by the Stoics related to, and more specifically based on, the Stoic notion of apodeixis. (Mates 1961, 63, rejects this, but without convincing reasons, see below.)

This relation would naturally be as follows. We are told in (C) (i) that the Stoic anapodeiktoi are syllogisms (and thus valid arguments) which need no apodeixis (see above with fn.9) and (ii) that this is so because "it is immediately evident that they are conclusive". Substitution in (C) of the definiens for the definiendum of the more generic definition of apodeixis (D)

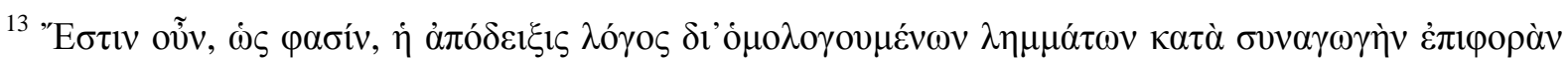

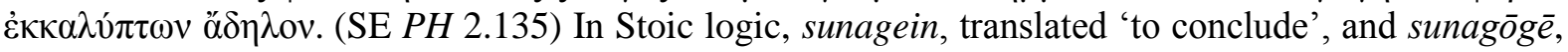
translated 'concluding', are semantic; epiphora, translated 'conclusion', is syntactic.

${ }^{14}$ Perainein and sunagein appear to be used synonymously in Stoic logic, and express that something is (validly) concluded. Validity is expressly mentioned in SE PH 2.137.

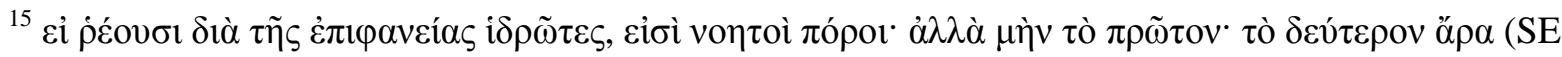
PH 2.142).
} 
yields: (i) an anapodeiktos needs nothing that makes it more easily grasped/graspable than it already is, and (ii) this is so because it is immediately evident that it is conclusive. Now 'being evident' is a Stoic epistemic term, and if something is 'immediately evident' this would imply that it is as easily grasped as things can be. From this it would follow that there is nothing more easily grasped that can be used on it to make it more easily graspable. ${ }^{16}$ This substantiates the suggestion that the demonstrations (apodeixeis) in (C) of which the indemonstrables (anapodeiktoi) have no need are those defined in (D): The most plausible and decisive explanatory answer to the question why something needs nothing that makes it more easily grasped or graspable than it already is would be: because it is already easily graspable to an extent that nothing can make it more easily graspable. ${ }^{17}$ By definition (D), in terms of Stoic apodeixis this yields: because it cannot be demonstrated; and that is, because it is indemonstrable. So the anapodeiktoi are not in need of a demonstration since they are indemonstrable. I propose that this is the link in Stoic logic between the Greek term anapodeiktos with the intended meaning 'indemonstrable' and the phrase 'no need of a demonstration', which provides an explication of a particular use of the term in that meaning. For, note that here we have a case of indemonstrability that is unusual in the following sense: it is combined not with the impossibility to realize the usual end of demonstration (say, cognitive access to the demonstrandum), but instead with the fact that the usual end of demonstration is already realized without demonstration. ${ }^{18}$

\footnotetext{
${ }^{16}$ I take it that for the Stoics 'being immediately evident' ( $\left.\varepsilon \tilde{v} v \alpha \imath \pi \varepsilon \rho \iota \varphi \alpha v \varepsilon \grave{\zeta}\right)$ does not admit of degrees. I also assume that those for whom things are immediately graspable are people with the relevant rational skills and information. For example, someone without mastery of the notions of argument, premises, conclusion and formal validity may not find the indemonstrables immediately graspable. (Moreover, indemonstrables can be of great complexity; the immediate evidence concerns their form, and an indemonstrable will only be immediately evident once its form has been recognized.) I bypass any further questions regarding the descriptive or normative nature of this evidence, since this is not relevant to my main points.

${ }^{17}$ Just as 'it is light' is only evident to a person who understands the sentence 'it is light' and grasps the Stoic proposition 'it is light', so the indemonstrables are evident only to those who have completed their development into fully rational beings. (See also previous note.) By emphasising that the syllogismhood of the indemonstrables needs no demonstration, where 'demonstration' is understood as the Stoic epistemic term, I take no stance on the question whether the Stoics were logical psychologists or logical anti-psychologists. Rather, the evidence of the indemonstrables is entirely compatible with the assumption that for the Stoics what makes the validity of their indemonstrables evident is a logical as opposed to psychological feature.

${ }^{18}$ For the Stoics, there are truths that are non-evident, so satisfying one necessary condition for being demonstrable -demonstrations are by definition of the non-evident- while failing to satisfy the other, say that there is a valid argument from evident premises for them. 'The number of stars is odd' or 'The number of stars is even' (whichever is true) is an example. Then there are truths that may satisfy the second necessary condition, but do not satisfy the first, because they are evident. Cf. Sextus' discussions of demonstration, SE $P H$ 2.135-143, M 8.299-314.
} 
Further support for the solution. Of interest is in this context a passage in Apuleius' $D e$ Interpretatione (Peri Hermeneias) which offers a threefold distinction for the Latin term indemonstrabilis (translating, no doubt, anapodeiktos, see Kneale \& Kneale 1962, 164 and below) and states which of these is used for the first four Peripatetic syllogistic moods - the correlates in Aristotle's syllogistic to the Stoic five kinds of indemonstrables.

(G) Now ... the first four are called indemonstrabilis - not because they cannot be demonstrated, like the measurement of the whole of the ocean, nor because they are not yet demonstrated, like the squaring of the circle, but because they are so simple and so evident that they do not need a demonstration. (Apul. Int.205.21-206.5, tr. Barnes modified) ${ }^{19}$

As Barnes 2007, 272-3 points out, the passage does not say that this threefold distinction is one of linguistic meanings and we have no reason to assume that it is meant to.

In line with the explanation of the incongruence regarding anapodeiktos I just offered, passage (G) lends itself to the following interpretation. First, the ancients did not, for what we know, have a grammar book that explained to them the two meanings of alpha-privativeprefixed verbal adjectives ending in '-tos' (which is paralleled by the Latin '-ibilis' and 'abilis') that I mentioned earlier. Rather, we can assume that they had as part of their ordinary linguistic aptitude (and possibly without reflection) the knowledge that any meaning of anapodeiktos / indemonstrabilis would have to fit one of the two options: indemonstrable or undemonstrated (or in alternative translation, unprovable or unproved). Thus retrospectively we may be able to discern in any of Apuleius' explications which of the two meanings it involves. Apuleius' distinction is threefold, since from his, or rather his source's, perspective, there were three distinct pertinent applications of indemonstrabilis, each related to a distinct kind of situation. He offers an example of each: (i) Situations in which it is humanly impossible to obtain a demonstration of something, with the result that the envisioned

19 ... igitur ... primi quattuor indemonstrabiles nominentur, non quod demonstrari nequeant, ut universi maris aestimatio, aut quod non demonstrentur, sicut circuli quadratura, sed quod tam simplices tamque manifesti sint ut demonstratione non egeant (Apul.Int.205.21-206.5). The text is slightly corrupt. I adopt Barnes' reading, and with Barnes 2007, Ramsey 2017 among others, I assume that Apuleius provides a three-fold distinction. With Ramsey 2017, 26-7 and the majority of manuscripts, I read nondum (not yet). Apuleius' first two examples seem a tad out of date. 
outcome of the demonstration is not obtained: the measure of the entire ocean; (ii) situations in which, although it may be humanly possible, a demonstration of something has not (yet) been obtained: the squaring of the circle; (iii) situations in which something one usually expects a demonstration to provide, i.e. simplicity and evidence, is already present before any demonstration has been attempted, and for that reason cannot be (and is not) provided by demonstration: (the syllogismhood or validity of) certain basic syllogisms.

Here is an analogy to illustrate the main point of the distinction between (i) and (iii). The goal is to fill a glass with water. The expected outcome is to have a glass full of water. Take case (ii) first. It would compare with the situation in which a functional glass is empty, and hence has not (yet) been filled and is unfilled. Case (iii) would compare to a situation with a full glass of water. You cannot fill a full glass of water with water. A full glass is unfillable, because it is already full. At the same time, there is no need for it to be filled, since the intended outcome of filling a glass with water, a glass full of water, is already achieved. Case (i) might compare to a situation with a glass that has a sieve as bottom. Again you cannot fill the glass with water. It is unfillable. Still, the last two situations are fundamentally different: once the intended outcome cannot be achieved, once the intended outcome is already realized.

Although in either of (i) and (iii) the situation is such that the syllogism is indemonstrable, and linguistically both (i) and (iii) would permit the translation 'indemonstrable', metaphysically the difference between them is as significant as that between (i) and (ii), and (ii) and (iii), respectively. A natural way to express succinctly what is significant about (iii), in contrast to (i) and (ii), is to say that no demonstration is needed. The meaning of the term is not thereby given. What distinguishes (i) from (iii) is not a matter of meaning of the expression anapodeiktos. It is a way of explaining two fundamentally different situations in which the same expression is used with the same meaning. Whether this meaning is being indemonstrable or being undemonstrated is not completely conclusive in (G). What is conclusive is that ultimately the syllogisms at issue need no demonstration because they are indemonstrable: If for some reason the intended meaning was undemonstrated, then the reason for the syllogism's being undemonstrated would be its indemonstrability.

Interim result. Both Sextus in passage (C) and Apuleius in passage (G) report the application of the term anapodeiktos (indemonstrabilis) in the context of syllogistic. (So do 
(A) and (B)) This makes it likely that they both report the same later ancient tradition of explaining anapodeiktos as used of syllogisms. If we additionally combine the results from passages (C) and (D) with those from (G), the balance tips toward the meaning 'indemonstrable', and I will assume that this was the intended meaning. ${ }^{20}$ Either way, looking back, Apuleius' demarcation of (iii) from (i) and (ii) can be used to better understand Sextus' and Diogenes' reports that the Stoic anapodeiktoi were syllogisms that are not in need of demonstration.

Residual question. It may still seem puzzling why in some sources the Stoics in their syllogistic explained the term 'indemonstrables' by 'need no demonstration' ((B) and (A)) rather than 'need no demonstration because they are self-evident' or 'need no demonstration because they are self-evident and as such permit no demonstration'. Texts (C) and (G) suggest that the accounts are abbreviated. And it can be readily explained why the abbreviation would retain the characterization 'need no demonstration'. In Stoic logic, what needs to be shown of certain syllogisms is that they are endpoints in an analysis, or backwards-worked deduction; and that is, that they themselves are not in need of justification by means of other syllogisms. Without such endpoints, syllogistic would be susceptible to infinite regress arguments, a kind of argumentation the Stoics were aware of (e.g. Chrysippus' Logical Investigations, PHerc 307, frg II). Assuming that in a syllogistic the guarantee of such an endpoint is the essential and primary concern, and the epistemic justification by immediate evidence is secondary, and the indemonstrability comes third, one can see how within Stoic syllogistic the account of the name anapodeiktoi was abbreviated to 'need no demonstration', and also how at a later time this explication may possibly have morphed into a definition. The incongruence between the expression anapodeiktos and the apparent Stoic definition of anapodeiktoi as being not in need of demonstration thus finds an

\footnotetext{
${ }^{20}$ Thus I do not share Barnes' conclusion that 'In any event, one thing is plain: Apuleius does not think that first figure predicative syllogisms are called 'indemonstrabilis' in the sense of 'unprovable'.' (Barnes 2007, 373). My view differs from Barnes's in two respects. First, I argue that at least for the Stoics and in later ancient texts, when used of basic syllogisms, anapodeiktos is used with the intended meaning that expresses the absence of a potentiality or possibility. Second, and more fundamentally, I argue that the Stoic term anapodeiktos, used of syllogisms, is by the Stoics understood as having its meaning derivative from the Stoic epistemic term apodeixis, rather than a special logical meaning (for which see below).
} 
easy explanation. ${ }^{21}$ Note also that in other texts, e.g. SE $M$ 8.228, text (H) below, the abbreviation appears to have gone the other way.

Apodeixis and syllogisms. This connection between the Stoic epistemological term apodeixis and their core logical term anapodeiktos can be exploited further. As noted above, for the Stoics, if something is 'immediately evident' this implies that it is as easily grasped as things can be, and so that there is nothing more easily grasped that can be applied to it. Now the things at issue are syllogisms (or formally valid arguments) and their syllogismhood (or formal validity). So we can say more specifically, it is as easily grasped as it can be that these anapodeiktoi are formally valid, and so there is nothing whose validity is more easily grasped that can be applied to them. Compare

(H) the [simple] indemonstrables are those [syllogisms] for which it is immediately clear (autothen saphes) that they conclude, that is that in them the conclusion follows from (suneisagetai) the premisses. ${ }^{22}$ (SE M 8.228)

This suggests that the Stoics also had cases of valid arguments that are in need of demonstration and, that is, for which there is something that is more easily grasped than them that is used in their demonstration. Consider the following two passages that report Stoic theory. (They are extensions of $(\mathbf{A})$ and $(\mathbf{B})):^{23}$

$(\mathbf{B}+)$ For they say [the anapodeiktoi] are the arguments which are not in need of demonstration (apodeixeōs) for the establishment of their own conclusiveness but are

\footnotetext{
${ }^{21}$ The identification within syllogistic of indemonstrability and lack of need for demonstration is not unique to the Stoics. In the commentary to his translation of Aristotle's Posterior Analytics, Barnes identifies Aristotelian uses of anapodeiktos in which 'being indemonstrable' and 'not being in need of demonstration' appear to be used interchangeably (Barnes 1994, 95).

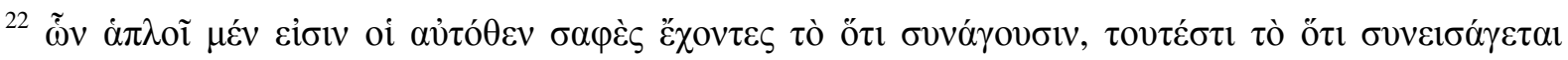

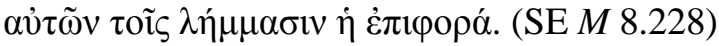

${ }^{23}$ The expression 'they say' marks $(\mathbf{B}+)$ out as reliable, despite the fact that it is part of a Sceptic refutation of Stoic doctrine. This is common in Sextus. I assume that Sextus is here drawing on the same - intermediate - source on which he draws at SE $M$ 8.223, as is frequently the case in the two works.
} 
demonstrative (apodeiktikous) of the fact that the other syllogisms, too, conclude. ${ }^{24}$ (SE PH 2.156)

(A+) And there are some [arguments] that are indemonstrable(s) (anapodeiktoi) since they do not need a demonstration (apodeixeōs), a different number according to different [Stoics], five according to Chrysippus. ${ }^{25}$ Through these every argument is composed (pleketai). ${ }^{26}$ (DL 7.79)

Both texts use the noun apodeixis saying that the anapodeiktoi do not need an apodeixis, and both relate the anapodeiktoi to other valid arguments or syllogisms. (This further confirms that for the Stoics the phrase 'needs no apodeixis' is not intended as a definition of anapodeiktos. It is in the context of comparison with other syllogisms that it becomes the crucial characteristic of the anapodeiktoi: 'since' in $\mathbf{A}+$, 'but' in $\mathbf{B}+$.) $(\mathbf{B}+)$ spells out this relation. The indemonstrables are 'demonstrative of the fact that the other syllogisms, too, conclude'. Indirectly, then, by using again the definition of apodeixis in (D), here we obtain information about something that Stoic analysis does: it makes things, more precisely the validity of non-indemonstrable syllogisms, easier to grasp.

We know that the relation between the indemonstrables and the other syllogisms is that the latter can be reduced by analysis via one or more of the Stoic themata, or some other Stoic inference rule, into the former (DL 7.78, Bobzien 1999, 2019). So this relation too can be expressed in epistemic terms. We can assume (we do not know) that a demonstration (apodeixis) of a syllogism $S$ would involve an analysis that reduces or analyses $S$ by way of one or more themata into one or more syllogisms that are more obviously conclusive than $S$ itself. For a syllogism not to be in need of a demonstration is thus a complex property that combines epistemic and logical elements. First, it is its validity that is evident or as easy to

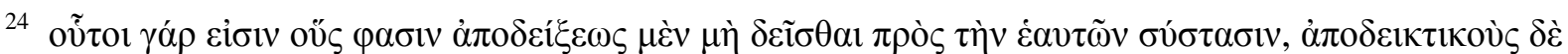

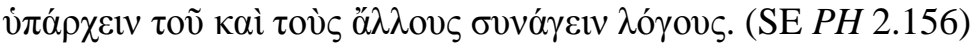

${ }^{25}$ It would be useful to know more about this alleged disagreement about the number of (kinds of) indemonstrables and what criteria were used to justify the different Stoic choices. However there is no surviving evidence. From later ancient logic texts we may conjecture that later Stoics may have added multi-conjunct or multi-disjunct syllogisms, or simply counted Chrysippus' multi-disjunct fifth syllogism as a sixth syllogism, or possibly added the later so-called wholly hypothetical syllogisms. But all this is uncertain. (No text suggests that the second indemonstrables were ditched, see below.)

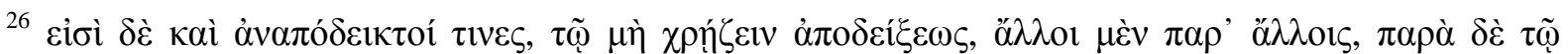

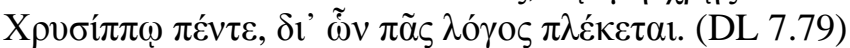


grasp as can be. This implies second, that even if it could be analysed by use of any thema $(t a)$, the validity of the resulting syllogism would be no more easily graspable than the original syllogism itself.

Apodeixis and analysis. En passant, this provides insight in the difficult issue how the Stoics thought about the meta-logical elements of logical analysis. Remember that demonstrations are arguments. Thus the demonstration of an argument $A$ is itself done in the form of an argument, call it a meta-argument. It appears that such a meta-argument would have $A$ occurring in its conclusion, with validity or syllogismhood predicated of it; that it would have occurring in one premise a thema application; and in one or more separate premises an argument each. And the arguments (and presumably the thema) in the premises would have to be more easily grasped than $A$. Ideally, such meta-arguments should be indemonstrables, too. Not only are all our examples of Stoic demonstrations indemonstrables (e.g. (F) above); more importantly, this would also avoid a hierarchy of meta-arguments (see below).

Here is an example which uses the first thema and analyses a two-premise syllogism $A$ into another two-premise syllogism. Take as the syllogism whose syllogismhood is to be demonstrated, the following argument: 'it is day; but not: it is light; so not: if it is day, it is light'. Call it syllogism $A$. Note that syllogism $A$ is not a Stoic indemonstrable. Call the syllogism 'if it is day, it is light; but: it is day; so it is light' syllogism $B$. Note that syllogism $B$ is a first indemonstrable. Recall that the Stoic first thema is

(I) When from two <propositions> a third is deduced, then from either of them together with the/a contradictory of the conclusion the/a contradictory of the other is deduced. $^{27}$ (Apul. Int.209.12-16)

The meta-argument then is

27 ... appellaturque a Stoicis prima constitutio vel primum expositu. quod sic definiunt: Si ex duobus tertium quid colligitur, alterum eorum cum contrario illationis colligit contrarium reliquo (Apul.Int.209.11-14). Apuleius' choice of 'expositu' ('bare', 'exposed') as one possible translation of 'thema' indicates that the themata were considered as evident. 
Premise 1 If 'if it is day, it is light; but: it is day; so it is light' is a syllogism, then 'it is day; but not: it is light; so not: if it is day, it is light' is a syllogism.

Premise 2 But 'if it is day, it is light; but: it is day; so it is light' is a syllogism.

Conclusion Hence 'it is day; but not: it is light; so not: if it is day, it is light' is a syllogism.

Premise 1 is an application of the first thema to syllogism $A$. Premise 2 is the antecedent of Premise 1. The conclusion is the consequent of Premise 1. It states the syllogismhood of syllogism $A$, i.e. of the argument whose validity is to be demonstrated. Thus the metaargument is a demonstration of syllogism $A$ that includes an application of the first thema in its first premise. By way of this demonstration, syllogism $A$ has been made more easily graspable, since it has been reduced by a more easily graspable thing (the meta-argument) to a more easily graspable thing. First, the demonstration or meta-argument is itself a first indemonstrable, and as such cannot be made more easily graspable. (Of course my articulation may be lousy: the representation of the argument might be improved on and the meta-argument made more easily graspable in that way.) Second, syllogism $B$, to which it has been reduced, is also a first indemonstrable, and as such cannot be made more easily graspable. Third, the first thema is also evident (cf. fn.27) and cannot be made more easily graspable (with the possibility of improved formulation again discounted). These demonstrations would be a species or subclass of the demonstrations covered by the Stoic definitions of demonstration (above texts (D) and (E).)

How do such demonstrations avoid a hierarchy of meta-arguments? If the meta-argument had, say, the form the non-indemonstrable syllogism $A$ has, one could require that it be made more easily graspable by a (meta-)analysis. If this (meta-)analysis also had the form of a nonindemonstrable syllogism, one could require that it be made more easily graspable by a (meta-meta-)analysis, and so on.

By removing the epistemic requirement that the arguments or arguments in the premises are to be more easily graspable than the argument in the conclusion, we can construct examples of Stoic meta-logical formulations of a step in an analysis in general. Still, while a demonstration (apodeixis) is an argument, analysis is a method of deduction or an instance of the application of that method. At most, one-step instances of that method would be 
arguments. However, our examples of analysis (SE $M$ 8.230-38) do not suggest that a onestep analysis needs to have the form of an argument.

Apodeixis and the role of the indemonstrables. If all this is correct, we can also answer a question about the Stoic indemonstrables that has puzzled some logicians and historians of logic. ${ }^{28}$ The Stoic first thema (above text (I)) seems to allow as a special case of application the analysis of a second indemonstrable into a first, and of a first indemonstrable into a second. Thus from the point of view of modern axiomatic systems, with the indemonstrables (or alternatively indemonstrable schemata) as axioms and themata as deduction rules, either the first or the second indemonstrables (or their indemonstrable schemata) are redundant. Now, it is not unheard of that logicians have proposed systems with redundant axioms. ${ }^{29}$ However, this is usually either an oversight that is adjusted at some later point, or there are some other reasons (e.g. retaining cut elimination) that make a redundant axiom useful or required. Neither case appears to capture what we know about Stoic syllogistic. We can assume that the Stoics were aware of the mutual reducibility of a first and a corresponding second indemonstrable, since this involves one of the two most basic applications of the first thema. So far no logical property has been identified that would require both first and second indemonstrables as axioms. However, as was already hinted by Michael Frede, it is plausible that with regard to the immediate evidence of their conclusiveness, the Stoics considered the two kinds of indemonstrables as on a par (Frede 1974, 131). Reducing a case of modus tollens to a case of modus ponens does not make the first clearer, since it is already immediately and evidently clear that it is valid. The Stoic criterion for the choice of their kinds of indemonstrables (or indemonstrable schemata) is then not motivated by minimizing their number qua number of axioms, or preserving a logical (as opposed to epistemic) property. Rather, it is motivated by retaining those kinds that cannot be made clearer to us with the help of analysis by logical inference rules such as the themata. Thus, demonstrability rather than axiomhood would be the criterion for the Stoic choice of basic syllogisms. If so, it

\footnotetext{
${ }^{28}$ See e.g. Ierodiakonou, 2006, 1.1 ; Bobzien 2019, p.244 fn.21. Mueller, 1979, p.205 and Hitchcock 2006, p.227 mention that a second indemonstrable is derivable from a first (but not the other way about). Mueller does not consider the question why the anapodeiktoi are anapodeiktoi.

${ }^{29}$ E.g. Axiom PM.4 in Principia Mathematica, shown to be redundant by Paul Bernay in 1926; Bernays, Paul, 1926, "Axiomatische Untersuchungen des Aussagen-Kalküls der Principia Mathematica", Mathematische Zeitschrift, 25: 305-320. doi:10.1007/BF01283841; Lukasiewicz showed that the axiom systems of the calculus of propositions proposed by Frege, Russell, and Hilbert each contained a different redundant axiom, e.g. Axiom P1 $(p \rightarrow p)$ in Hilbert's propositional calculus; some schemata in Gentzen's systems LK and LJ are redundant, cf. Gentzen 1934, 193.
} 
is not strictly correct when Frede $(1974,128)$ and Lukasiewicz $(1935,117)$ assert that the indemonstrables were called indemonstrables because their role is that of axioms. The fact that the rejection of the Two-senses Assumption allows us to make sense of the redundancy of one of the five kinds of Stoic indemonstrables should speak in favour of this rejection. Of course the Stoics, like Medieval and contemporary logicians, may have allowed for redundant axioms for ease of application. Even in this case, the ease gained by having both the first and second indemonstrables is not great. More significantly, even in this case it would be hard to find a reason for the choice of those two other than their immediate evidence.

Apodeixis and deduction. It is a common, if incorrect, assumption that the demonstrations which the alpha privative in an-apodeiktos counters are Stoic deductions. Scholars generally assume that the apodeixis that corresponds to the anapodeiktoi is Stoic deduction and the claim that the anapodeiktoi need no apodeixis is another way of saying that they need no analysis. For example, this assumption is made by Mates 1961, 63, Mueller 1978, 11 and Frede 1974, 132, and appears to be presupposed in Barnes' and Hitchcock's reasoning. It is also commonly invoked or presupposed in the argument that anapodeiktos should be translated as unproved or undemonstrated rather than unprovable or indemonstrable: for example that it is false that anapodeiktoi cannot be analysed, since matching first and second anapodeiktoi appear to be mutually analysable. There is however (i) no evidence for the assumption that apodeixis in texts $(\mathbf{A}+),(\mathbf{B}+),(\mathbf{C})$, and in Stoic logic generally, means something like deduction or analysis. No reliable Stoic source uses apodeixis or its cognates to refer to or describe a Stoic analysis or its result. Instead, Stoic terms commonly used are logos, analusis, analuein, sullogismos, sunagōgē, sunagein, perainein, kata synagōgēn, etc. (Passages (B+), (H) and (I) are examples.) In particular, no definition of apodeixis in this sense is ever supplied. By analysing a non-indemonstrable one does not per se make it more easily graspable. One just applies some logical apparatus. ${ }^{30}$ There is also (ii) no need for the

30 It has been suggested that strictly speaking in Stoic sequent logic, the anapodeiktoi are not analysable either. Bobzien argues that Stoic analysis is such that once an axiom has been reached no further rule can be applied (Bobzien 1996, 2019). Matching first and second indemonstrables are then not analysable into each other. Barnes, too, seems to think this $(2007,371$, '[t]he five Chrysippean unproveds are the five syllogistic forms which the Chrysippean system does not prove.') though he does not say why. If this is correct, then for every non-indemonstrable syllogism (or formally valid argument) there would exist a demonstration (apodeixis) or a concatenation of demonstrations that corresponds to some analysis of it. The demonstrations would be meta-arguments of the type given above. Still, the analysis of an argument would not be its demonstration, as the examples of analysis in Sextus (SE $M$ 8.235-7) illustrate. Also, the redundancy of the first and second indemonstrables is retained even if indemonstrables, once reached, cannot be analysed further. The difference between 
assumption, since as we have seen there is a historically documented alternative notion of apodeixis that provides an explanation of the occurrence in Stoic logic of apodeixis and anapodeiktos that explains the epistemic language in those passages, makes do with one documented - Stoic notion of apodeixis and removes the apparent incongruence in the explication 'no need for apodeixis' in $(\mathbf{A}+),(\mathbf{B}+),(\mathbf{C})$.

So, since there is an alternative, epistemic, notion for which the expression apodeixis is used, and $(\mathbf{A}+),(\mathbf{B}+),(\mathbf{C})$ invoke epistemic elements, the identification in Stoic syllogistic of apodeixis with deduction is unsubstantiated and unnecessary. ${ }^{31}$ Historically, we can see how such an identification arose possibly already in late antiquity. Peripatetics like Alexander use apodeixis and apodeiknunai ('to demonstrate') in order to express the proof of the validity of an Aristotelian syllogism (cf. Barnes et al 1991, 20-21). Such a proof would be the Peripatetic analogue to a Stoic analysis. This use of apodeixis and cognate terms is likely to have eclipsed the Stoic distinction between the analysis of an argument and what would be its apodeixis. This historical development does of course have no impact on the fact that, for the reasons just given, any argument against the translation of 'indemonstrable' based on the assumed identification in Stoic logic of apodeixis and deduction or analysis fails.

There is thus a web of reasons why the standard translation 'indemonstrable' can be retained and why the translations 'indemonstrable' or 'unprovable' are preferable to 'undemonstrated' and 'unproved'. Historically, 'indemonstrable' may be preferable. Either way, it seems not advisable to mingle Stoic epistemic and Stoic logical terminology in translations (as we find it e.g. in Mueller 1978, Hitchcock 2006). Whichever modern-language word family one uses for apodeixis, apodeiknumi, apodeiktikos, anapodeiktos is best reserved for those epistemic terms and avoided for translations of the aforementioned logical terms. Failure to do so just adds to the muddle.

Apodeixis and dialectic. There are three mentions that relate demonstration with Stoic dialectic in Diogenes Laertius. One is the anecdote that Chrysippus told Cleanthes that all he

demonstrability and analysability is thus retained in the choice of indemonstrables. If it was just analysability, we would expect the first or the second indemonstrables to be eliminated.

${ }^{31}$ So, even though it may be correct that indemonstrables need no analysis in Stoic sequent logic, this is not what texts $(\mathbf{A}),(\mathbf{B}),(\mathbf{C})$ were intended to express where they say that Stoic indemonstrables need no demonstration. At the very most, analysis would be a species of apodeixis, but even for this there is no indication in our sources, and it does not sit well with our texts. 
needed were the views (dogmata) of Stoic philosophy, he would find the proofs or demonstrations (apodeixeis) for them himself (DL 7.179). Here a demonstration is clearly an argument in support of a philosophical statement, not an argument about the validity of a complex syllogism. The other two are in my view related to the same topic. A Chrysippean book title 'On the fact that the ancients admit dialectic along with demonstrations' (DL 7.201) and a summary statement that the Stoics say 'that the consideration (or theory) of syllogisms is most useful; for it makes manifest that which can be demonstrated (to apodeiktikon)' (DL 7.45). Both sentences are found in an epistemological context. The second is followed by definitions of argument, syllogism and then of demonstration (above (D)). In both cases the point appears to be that dialectic, and in particular syllogistic, is at the service of demonstrating philosophical tenets. ${ }^{32}$ The epistemological context in both cases would seem to rule it out that that which is or can be demonstrated by demonstrations is the validity of non-indemonstrable syllogisms.

Refutation of Mates' argument against a single Stoic notion of apodeixis. My main contention has been that the notion of demonstration that gives rise to the Stoic term 'indemonstrable' is the Stoic epistemic notion of demonstration for which we have extant definitions. Why, one may ask, is this assumption virtually absent in the literature on Stoicism, particularly, since there is no evidence of any other Stoic notion of demonstration, let alone another definition? Perhaps in contemporary scholarship this absence has gained support via Benson Mates' highly influential monograph Stoic Logic (Mates 1961), which I mentioned at the outset of this paper.

Mates writes that in the classification of fundamental valid arguments (1) 'the term "demonstrated" (apodeiktikos) has a far different meaning from that which it has in the contexts of' Sextus' report of the Stoic demonstrative arguments and definition of demonstration; and that hence (2) 'it is clear that' 'the sense of "demonstrate" ... involved in the Stoic term "undemonstrated" as applied to the basic arguments' 'is not the same sense involved in the word "demonstrative" [i.e. apodeiktikos]' (Mates 1961, 63).

\footnotetext{
${ }^{32}$ The book title at DL 7.201 has been given a more complex interpretation by Brunschwig 1995, picked up in Bronowski 2019, 26-7.This seems to me to be too speculative, although it is consistent with what I suggest.
} 
Mates offers the following two points in support for his claim. (a) 'an invalid argument would be non-demonstrative [i.e. ouk apodeiktikos], but it would not be undemonstrated [i.e. anapodeiktos].' (ibid.) and (b) '[c]onversely, the "milk" and "pores" arguments, which were examples of demonstrative arguments, are also examples of the type I undemonstrated argument' [i.e. examples of first indemonstrables] (ibid. fn.27; for the "pores" argument see text (F) above). However, Mates makes a number of questionable assumptions, and once these have been sorted, his argument crumbles.

First, he assumes without comment that the correct translation of anapodeiktos is 'undemonstrated'. We have seen that this assumption is not warranted.

Second, Mates' claim (1) has a false presupposition, namely that a synonym of the Stoic term anapodeiktos occurs in the context of Sextus' reports of Stoic demonstrative arguments (i.e. SE $P H$ 2.135-143, M 8.299-314). It does not occur in that context. What occurs in that context is the expression 'not demonstrative' (ouk apodeiktikos). Mates wrongly assumes that the Stoic terms 'not demonstrative' and 'indemonstrable' (anapodeiktos) are synonymous, or at least that the first entails the second. This is however not so. In Stoic logic only the use of 'not' (ouk / ou / ouch / ouchi) in front of an expression provides contradictory opposites. The alpha privative, though a kind of negation, does not guarantee contradictoriness (DL 7.70 with Apul. Int.191.6-11, SE $M$ 8.103). There is then nothing problematic in there being things that are both not demonstrative (ouk apodeiktikos) and not an indemonstrable (anapodeiktos). Mates' justification (a) of his claim (1) hence also loses its force. ${ }^{33}$

Third and related, Mates' claim (1) appears to wrongly presuppose that the Stoic expressions 'anapodeiktos' and 'ouk apodeiktikos' are used as part of a discussion of the same distinction, namely a distinction of arguments (logoi). Mates disregards (although he mentions it earlier in the same chapter) that the Stoic distinction between apodeiktikoi and ouk apodeiktikoi is a distinction of arguments (logoi). The Stoic expressions are short for 'apodeiktikoi logoi' and 'ouk apodeiktikoi logoi' respectively. By contrast, 'anapodeiktoi' is short for 'anapodeiktoi sullogismoi', and the anapodeiktoi are part of a two-fold distinction of syllogisms or formally

\footnotetext{
${ }^{33}$ The expression anapodeiktos appears to have been used as opposite both to apodeiktikos (active form) and to apodeiktos (passive form). There is no ancient Greek word anapodeiktikos. The Stoic use the active form, so the question whether in their view something could have been both apodeiktos and anapodeiktos does not occur.
} 
valid arguments. In this respect, too, there is nothing problematic to find one expression that negates an aspect of demonstration in the definition by division of one kind of objects and another expression that negates a different aspect of demonstration in the context of a different kind of objects.

Fourth and related, Mates' claim (1) appears to wrongly presuppose that the negating element in the Stoic expressions anapodeiktos and ouk apodeiktikos have the same function. They do not have the same function. Invalid arguments are not demonstrative (ouk apodeiktikos), since they are not demonstrations. A demonstration is the same as a demonstrative argument, and it presupposes validity (SE $P H$ 2.135-143, SE $M$ 8.301-314, Mates 1961, 60-3, Barnes 1980, Allen 2008, Study III.5). By contrast, indemonstrable syllogisms (anapodeiktoi) are indemonstrable, since no demonstration can be given of their validity or syllogismhood, because their syllogismhood is already fully evident and hence maximally graspable. This difference does not impact the fact that in both cases the very same notion of demonstration (apodeixis) is at issue. The dissimilarity that the demonstrandum in one case is a simple conclusion (e.g. 'there exist imperceptible pores', above $(\mathbf{F})$ ), in the other a sentence that contains reference to an entire argument, presumably in the subject expression, and its formal validity or syllogismhood, presumably in the predicate expression, does not affect the truths that the underlying notion of demonstration is the same and that it is the Stoic epistemic one for which we have definitions. Hence, Mates inference (2) is faulty, since it does not follow that if the two expressions 'not demonstrative' and 'indemonstrable' have different meanings, so do the corresponding positive expressions (apodeixis and apodeiktikos).

Likewise, fifth, there is no problem with Mates' second allegedly problematic case (b). A demonstration like $(\mathbf{F})$ reveals its conclusion and makes it more easily graspable than its premises are. At the same time, syllogisms like (F) are indemonstrables, since the fact that they are formally valid or a syllogism is fully evident and as such does not permit a demonstration, because the function of a demonstration is to reveal something that is not evident or at least to make it more graspable. Moreover, the word apodeiktikos, which Mates assumes to be related solely to the passages that explain the definition of apodeixis and its synonym apodeiktikos logos (implied, SE $M$ 8.311, 314, SE $P H$ 2.140, 143), actually occurs also in the context of the indemonstrables (SE $P H 2.156$, quoted above as text (B+)). 
So, pace Mates (Mates 1961, 63), we have every reason to assume that 'the sense of "demonstrate" ... involved in the Stoic term "undemonstrated" [i.e. anapodeiktos] as applied to the basic arguments' is 'the same sense involved in the word "demonstrative" [i.e. apodeiktikos]'.34

Results. It is the principal point of this paper that in their syllogistic (sequent logic, theory of deduction ...), where the Stoics use the word apodeixis and its cognates they use their epistemic notion of apodeixis of which definitions and explications have survived. On this basis, we can conclude that there is an array of jointly compelling reasons for assuming that the translation 'indemonstrable', understood as meaning 'cannot be demonstrated' is accurate: It makes sense of the Stoic explication 'no need of demonstration'. It avoids the difficulties with passage (C) which translations like 'unproved' introduce. It makes do with just one Stoic notion of demonstration, the one of which we have two Stoic definitions. It can explain the relation between Stoic analysis and Stoic demonstration. It can explain why one Stoic kind of indemonstrables, although it appears redundant, is retained by the Stoics. It can make sense of the - apparent - difficulties on the basis of which Mates infers that the indemonstrables have nothing to do with Stoic demonstration.

\footnotetext{
${ }^{34}$ A passage in Sextus suggests that some Stoics called all their syllogisms indemonstrables, both simple and non-simple ones, where non-simple ones are those analysable into simple ones. This has generated much discussion, but no convincing solution. Frede 1974, 130, compellingly shows that the first meaning of anapodeiktos in (C) cannot refer to all Stoic syllogisms, simple and non-simple, and also refutes Mates' self-declared 'entirely conjectural' suggestion regarding the meaning of "undemonstrated" as applied by the Stoics to the five types of basic arguments (Mates 1961, 64 with fn.30). Frede's own suggestion is however similarly forced. I offer two alternative explanations. Sextus is generally a most reliable source for Stoic logic where he reports Stoic theory. However, in this case I believe that it is plausible that the occurrence of anapodeiktoi is an - inadvertent - error, whether introduced by Sextus or his non-Stoic source. The distinction of these two types of Stoic indemonstrables occurs nowhere else. It is not picked up by Sextus later in the text. There is not even a hint in the following long report of Stoic analysis that would explain why the non-simple syllogisms are indemonstrables. Usually at the end of a sceptical argument Sextus repeats his initial thesis. In this case, the sceptical argument is in SE M 8.239-243, where no mention of non-simple indemonstrables is found. If on the other hand the text must be left as it is, here is my best offer. The Stoics often use the same philosophical expression in a wider and in a narrower sense. Assuming a wider sense for all syllogisms, non-simple syllogisms are then indemonstrable in this wider derivative sense. An analysis uses indemonstrables and themata, and we can assume that the themata were considered evident. (Apuleius offers expositum, English 'bare' or 'exposed', as one of two translation of the Stoic term thema, Apul.Int.209.10-12.) So derivatively, as the result of the use of evident rules to reduce in evident steps the non-simple syllogisms to evident syllogisms, the non-simple syllogisms inherit the evidence of this procedure. This is of course entirely conjectural.
} 
Coda. Let me end with a historical note. In Latin texts from antiquity the only occurrences of indemonstrabilis are thirteen in Apuleius' De Interpretatione (listed in Belli 2014, 76) and sixteen in Boethius' logical writings (Belli 2014, 53), including two used of Peripatetic syllogistic modes (Boeth.Syll.Cat.823A = 75.14-15 Thomsen Thörnqvist) and importantly one of the Stoic indemonstrables (Boeth.Com.Arist.Int.II 351.8 Meiser $^{35}$ ). We can assume that both authors translate from a Greek source the expression anapodeiktos (cf. Kneale \& Kneale 1962, 164 fn.3, Barnes 2007, 372; Belli 2014, 65 and assumed passim; Ramsey 2017, 235) and it is likely that they arrived at this translation independently of each other (Belli 2014, 59-60). The term then makes its way into medieval philosophical and theological texts (Belli 2014, 68-74) and into the earliest Latin translations of Sextus and early translations of Diogenes Laertius, ${ }^{36}$ and from there into English and other modern languages, languages in which the ambiguity is no longer present, and nolens volens a choice is made. ${ }^{37}$ So, this development provides a historical explanation of the predominance of the translation of anapodeiktos as 'indemonstrable'. It comes to us via an Anglicisation (etc.) of the Latin indemonstrabilis, with presumably unnoticed disambiguation. So, not only is 'indemonstrables' a philosophically correct rendering of the Stoic anapodeiktoi, it is also the historically grown translation.

\footnotetext{
35 'And he makes this syllogism in the second hypothetical mode, which he calls indemonstrable, in this way: if the first is, the second is; but the second is not, hence the first is not.' (Fecit autem hunc syllogismum in secondo modo hypothetico quem indemonstrabilem vocat hoc modo: si primum est, secundum est; sed secundum non est, primum igitur non est. Boeth.Com.Arist.Int.II 351.7-10, Meiser.)

${ }^{36}$ Sextus, first Latin translation of the Outlines of Pyrrhonism, Henricus Stephanus (1562), p.93, indemonstrabiles; Sextus, first Latin translation of Adversos Mathematicos, Hervet (1569), p.425, SE M 8.223: 'indemonstrabilis', 'indemonstrabiles', 'quae non opus habent demonstratione'. Diogenes Laertius: The first translation of Diogenes into Latin, by Henricus Aristippus, is lost. The $2^{\text {nd }}$ Latin translation, Traversari (1455, MS), was originally completed between 1427 and 1433. Traversari obviously had difficulties rendering anapodeiktos. On the relevant page (carta 102 verso, which includes DL 7.79-81) he leaves a gap for the translation of anapodeiktoi before dicuntur, as if to fill in later perhaps after some research on the Greek term. He avoids the Latin noun for anapodeiktos in the accounts for the first, second, fourth and fifth indemonstrables; for the third he decides on tertia demostrativa.

${ }^{37}$ Sextus, first English translation of the Outlines of Pyrrhonism, Thomas Stanley (1655-60), part XII, p.502, 'Indemonstrable'; Diogenes Laertius, first English translation (Fetherstone et al 1696), 'Anopodeicti'; Diogenes Laertius, second English translation, Yonge (1853), 'demonstration', indemonstrable' (DL 7.78), 'demonstration', 'not demonstrated' (DL 7.79). Sextus, French tr., Huart (1725), indémonstrables', Sextus, German tr., Buhle (1801), 'indemonstrabeln'.
} 
Acknowledgements: I thank James Allen and Wim Vanrie for most helpful comments, Chiara Martini for pointing out an ambiguity in the initial formulation of my example, and the audience at the Oxford Workshop in Ancient Philosophy for stimulating discussion.

\section{Bibliography:}

Allen, James. 2008. Inference from Signs: Ancient Debates about the Nature of Evidence. Oxford: OUP.

Annas, Julia \& Barnes, Jonathan. 2000. Sextus Empiricus: Outlines of Scepticism. Cambridge: CUP.

Barnes, Jonathan. 1980. 'Proof destroyed', in Schofield, Malcolm, Burnyeat, Myles \& Barnes, Jonathan, Doubt and Dogmatism: Studies in Hellenistic Epistemology (Oxford), 16181.

Barnes, Jonathan. 1985. 'Theophrastus and hypothetical syllogistic' in Wiesner, Jürgen. Aristoteles - Werk Und Wirkung, Bd I, Aristoteles Und Seine Schule (Berlin), 557-576. Reprinted in Barnes, Jonathan. 2012 (Oxford), 413-32, Logical Matters, as 'Theophrastus and Stoic logic'.

Barnes, Jonathan et al., 1991. Alexander of Aphrodisias: On Aristotle Prior Analytics 1.1-7. London: Duckworth.

Barnes, Jonathan. 1994. Aristotle: Posterior Analytics. Translated with a Commentary. $2^{\text {nd }}$ edn. Oxford: Clarendon Press.

Barnes, Jonathan. 2003. 'Proofs and syllogisms in Galen', in Galien Et la Philosophie: Huit Exposés Suivis de Discussions. (Geneva),1-24.

Barnes, Jonathan. 2007. Truth, etc. Oxford: OUP.

Belli, Margherita. 2014. 'Boethius, disciple of Aristotle and master of theological method' in Böhm, Thomas, Jürgasch, Thomas \& Kirchner, Andreas. Boethius as a Paradigm of Late Ancient Thought (Berlin), 53-82.

Bobzien, Susanne. 1996. 'Stoic Syllogistic.' Oxford Studies in Ancient Philosophy 14: 133192.

Bobzien, Susanne. 2019. 'Stoic Sequent Logic and Proof Theory.' History and Philosophy of Logic 40 (3): 234-265.

Bronowski, Ada. 2019. The Stoics on Lekta. Oxford: OUP.

Brunschwig, Jacques. 1995. 'Sur un titre d'ouvrage de Chrysippe: 'que les anciens ont admis la dialectique aux cotés de la démonstration', in Brunschwig, J. Études sur les philosophies hellénistiques (Paris), 233-50.

Buhle, Johann Gottlieb. 1801. Sextus Empirikus oder der Skepticismus der Griechen. Lemgo: Meyer. 
Bury, Robert Gregg. 1990. Sextus Empiricus: Outlines of Pyrrhonism. Buffalo, N.Y: Prometheus Books.

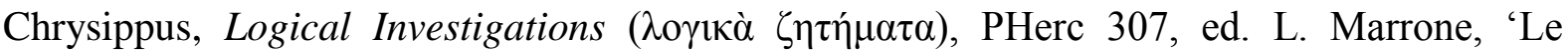
Questioni Logiche di Crisippo (PHerc 307)' in 1997. Cronache Ercolanesi 27: 83-100. [Log. Inv.]

Fetherstone et al.1696. Laërtius, Diogenes. The lives, opinions, and remarkable sayings of the most famous ancient philosophers. Volume 2. London: Edward Brewster.

Frede, Michael. 1974. Die stoische Logik. Goettingen: Vandenhoeck \& Ruprecht.

Gentzen, Gerhard. 1934. 'Untersuchungen über das logische Schließen. I.' Mathematische Zeitschrift 39 (2): 176-210. [English translation by M. E. Szabo: Investigations into Logical Deduction I'. American Philosophical Quarterly 1 (1964), 288-306. Also in M. E. Szabo,. The Collected Works of Gerhard Gentzen, Amsterdam 1969.]

Hankinson, Robert J. 2009. 'Galen on the limitations of knowledge' in Gill, Christopher, Whitmarsh, Tim \& Wilkins, John (ed.). Galen and the World of Knowledge (Cambridge), 206-242.

Hervet, Gentian. tr. 1569. Sexti Empirici viri longe doctissimi adversus mathematicos, Hoc est, adversus eos quo profitentur disciplinas, Opus eruditissimum Paris: Le Jeune.

Hitchcock, David. 2005. 'The peculiarities of Stoic Propositional Logic'. In John Woods, Kent A. Peacock \& A. D. Irvine (eds.), Mistakes of Reason: Essays in Honour of John Woods. (Toronto), 224-242.

Huart, Claude. tr. 1725. Sextus Empiricus. Les Hipotiposes ou Institutions Pirroniennes en trois livres. Presumably printed in Amsterdam.

Ierodiakonou, Katerina. 2006. 'Stoic logic.' in Blackwell Companions to Philosophy: A Companion to Ancient Philosophy (eds. M. L. Gill and P. Pellegrin) (Oxford), 505-29.

Kneale, W. and M. Kneale. 1962. The Development of Logic. Oxford: Oxford University Press.

Łukasiewicz, J. 1935. 'Zur Geschichte der Aussagenlogik.' Erkenntnis 5: 111-131. [Translated by the author from his 'Z historii logiki zdan', Przegląd Filozoficzny 27 (1934), 417-37. English translation as 'On the History of the Logic of Propositions ' by S. McCall in Polish Logic 1920-1939 (Oxford, 1967), 66-87.]

Mates, B. 1961. Stoic Logic. $2^{\text {nd }}$ edn. Berkeley/Los Angeles: University of California Press. (First edition 1953).

Meiser, Karl. 1880. Anicii Manlii Severini Boetii Commentarii In Librum Aristotelis Peri Hermenias. Leipzig: Teubner.

Mueller, Ian. 1978, 'An Introduction to Stoic Logic.' in Rist, John M. (ed.). The Stoics. (Berkeley / Los Angeles), 1-26. 
Mueller, Ian. 1979. 'The Completeness of Stoic Propositional Logic.' Notre Dame Journal of Formal Logic 20 (1): 201-215.

Ramsey, Emma. 2017. A Commentary on the Peri Hermeneias ascribed to Apuleius of Madaura. Doctoral Thesis, Royal Holloway, University of London.

Stanley, Thomas. 1701. History of Philosophy: Containing the Lives, Opinions, Actions and Discourses of of Every Sectionthe Philosophers of every Sect. $3^{\text {rd }}$ edn. Part XII, London: W. Battersby.

Stephanus, Henricus [Henri Estienne]. tr. 1562. Sexti Empirici Pyrrhoniarum Hypotyposeon libri III. Geneva, 1562.

Thomsen Thörnqvist, Christina. 2008. Anicii Manlii Severini Boethii de Syllogismo Categorico: Critical Edition with Introduction, Translation, Notes, and Indexes. Gothenburg: University of Gothenburg, Studia Graeca et Latina Gothoburgensia 68.

Traversari, Ambrogio. 1455. MS. Laertii Diogenis vitae atque sententiae eorum qui in philosophia claruerunt liber decimus et ultimus faeliciter explicit. Florence. Manuscript S.Marco 323 in the Biblioteca Medicea Laurenziana, (electronic copy CNMD10000114834). http://mss.bmlonline.it/s.aspx?Id=AWOS4v9JI1 A4r7GxMdi4\&c=LAERTII\%20VITAE\%20PHIPOSOPHORUM\#/book

Yonge, C.D. 1853. Diogenes Laertius: The Lives and Opinions of Eminent Philosophers. London: H. G. Bohn. 